\title{
Treatment of Auricular Hematoma with Compression Using X-ray Films
}

\author{
Ahmad Nasrat Al-juboori* \\ Ibn Sina College of Medicine, Al- Iraqia University, Baghdad, Iraq
}

\begin{abstract}
The auricular hematoma of the pinna occurs secondary to trauma and can present a therapeutic dilemma for ENT surgeon, and if untreated will ultimately result in a deformity commonly known as 'cauliflower ear'. Various treatments are employed to relieve the hematoma but no clear consensus exists on the best way to do so in order to produce the best cosmetic result. The aim of this article was to evaluate the outcome and complications of the treatment of auricular hematoma with compression using X-ray films in comparison with traditional method of compression using pressure by bandage. This study had been performed upon 25 patients presented with auricular hematoma from different areas in Al-Anbar Governorate during the period from June 2005 to September 2011, treated in Al-Ramadi and Al-Fallujah General Hospitals by the same surgeon. The patients were divided into two groups. Group A constituted by 15 patients who underwent incision, drainage and compression by bandage. Group B constituted by 10 patients who underwent incision, drainage and compression by X-ray films. After seven days of compression, the bandage or the $\mathrm{X}$-ray films were removed, and the state of the ear examined, if there was recurrence of the hematoma, re-drainage and compression was applied again. Follow up continued for the next six months for the possible future complications especially deformity of the pinna. The commonest cause behind hematoma was personal insult $(40 \%)$. The recurrence happened in one third of the patients in group $A$, while the recurrence of auricular hematoma not happened in Group B of the patients. This means, there was statistical significance in comparison of both groups.
\end{abstract}

From this article we concluded that compression of auricular hematoma by X-ray films was easy in use and fashioning, convenient, cost effective and there was no recorded infection or recurrence.

Keywords: Auricular hematoma; Cauliflower ear

\section{Introduction}

Auricular hematoma or hematoma auris is a collection of blood between the auricular cartilage and perichondrium [1]. Knowledge about it began, in antiquity, through artists, particularly Greek and Roman, and then Japanese in the $18^{\text {th }}$ century with their representation of cauliflower deformation of the ear on sculptures and paintings of pugilists and wrestlers [2]. The hematoma is usually produced by trauma, although occasionally the spontaneous rupture of a blood vessel may be the cause [1]. Acute auricular hematoma is common after blunt trauma to the side of the head. A network of vessels provides a rich blood supply to the ear, and the ear cartilage receives its nutrients from the overlying perichondrium. Prompt management of hematoma includes drainage and prevention of re-accumulation. If left untreated, an auricular hematoma can result in complications such as perichondritis, infection, and necrosis. Cauliflower or wrestle's ear may result from long-standing loss of blood supply to the ear cartilage and formation of neocartilage from disrupted perichondrium [3]. Pandya [4] demonstrated experimentally in rabbit's components of fibrosis, immature chondrogenesis and osteogenesis in the organizing hematoma. The hematoma occurs almost exclusively on the anterior surface of the auricle where the skin is tightly adherent to the underlying perichondrium, so that sharing forces applied to the ear separate the perichondrium from the cartilage. On the posterior surface, intervening aerolar tissue allows the skin to glide over the perichondrium [1]. Auricular hematomas are often encountered in a sports medicine practice, most commonly among wrestlers, but also in boxers, football and rugby players, and judo athletes [5]. A systematic review published in the Cochrane database reported that no particular method of managing a pinna hematoma is markedly more effective in achieving a favourable cosmetic outcome. However, the review does support the role of intervention, either by needle aspiration or by incision and drainage of the hematoma, rather than no treatment [6]. Aspiration alone, however results in a very high incidence of recollection until the perichondrium is again firmly adherent (about seven days). In order to prevent this, the following options have been devised; the use of moulded pressure bandages and splints [7] of various materials applied on both sides of the pinna, or a drain left in the incision site $[8,9]$, or a posterior incision, with excision of a disc of cartilage and placement of a suction drain $[10,11]$, finally through-andthrough 'mattress' or 'quilting' sutures to apply compression [12], with or without materials to distribute the compression more evenly.

The aim of this article was to evaluate the outcome and complications of the treatment of auricular hematoma with compression using X-ray films in comparison with traditional method of compression using pressure by bandage.

\section{Materials and Methods}

This study had been performed upon 25 patients presented with auricular hematoma from different areas in Al-Anbar Governorate during the period from June 2005 to September 2011, treated in AlRamadi and Al-Fallujah General Hospitals by the same surgeon. After taken a good history from each patient regarding the age, sex, duration and cause of the injury, as well as history of bleeding disorders. Examination of the hematoma with exclusion of other differential diagnosis as well as hematological investigations to rule out bleeding tendency and as a part of preparation for general anesthesia. The type of treatment discussed with patient family, and then agreement with patient consent had been taken. All the auricular hematomas were drained under general anesthesia by incising along an anatomical auricular crease. After evacuation of the hematoma and copious irrigation, the resultant skin flap was replaced in anatomical position. Here, the patients divided into two groups. Group A constituted by

*Corresponding author: Ahmad Nasrat Al-juboori, Assistant Professor and Otorhinolaryngologist, Head and Neck Surgeon (F.I.C.M.S.), Ibn Sina College of Medicine, Al- Iraqia University, Baghdad, Iraq, Tel: +9647902892674; E-mail: ahmednas2005@yahoo.com

Received January 26, 2013; Accepted February 21, 2013; Published February 28, 2013

Citation: Al-juboori AN (2013) Treatment of Auricular Hematoma with Compression Using X-ray Films. Gen Med (Los Angel) 1: 101. doi: 10.4172/2327-5146.1000101

Copyright: ( $2013 \mathrm{Al}$-juboori AN. This is an open-access article distributed under the terms of the Creative Commons Attribution License, which permits unrestricted use, distribution, and reproduction in any medium, provided the original author and source are credited. 
15 patients who underwent incision, drainage and compression by bandage. Group B constituted by 10 patients who underwent incision, drainage and compression by X-ray films, the X-ray films were sterilized and fashioned pre-operatively according to the shape and size of the hematoma. The X-ray films applied in both sides of the hematoma and fixed in position by nylon suture, in a figure of eight form of suturing. Incision sites were left open and dressed with antimicrobial ointment. No bolsters were placed. The patients were given one week of oral antibiotic therapy. After seven days of compression, the bandage or the $\mathrm{X}$-ray films were removed, and the state of the ear examined, if there was recurrence of the hematoma or development of infection or abscess, redrainage with antibiotics administration as well as compression against the hematoma was applied again. Follow up continued for the next six months either by regular visits or by phone calls for the possible future complications especially deformity of the ear. For ethical point of view the above mentioned hospitals had no objection for publication of these data in this article.

\section{Results}

A total number of patients with auricular hematoma were 25 patients, they ranged from 12-60 years old, and the mean age with standard deviation was 29 years \pm 2.4 years. Among them 21 patients (84\%) were male and four patients were female (16\%) (Table 1).

The onset of presentation happened mainly in the first 24 hours of the injury, sixteen patients presented in the first 24 hours, five patients presented in the second 24 hours and another two patients presented between 48-72 hours of the onset, while the remaining two patients after 72 hours.

The causes of auricular hematoma shown in table 2 revealed that Personal insult on the pinna happened in ten patients (40\%) which was the commonest cause behind auricular hematoma. Sport injuries happened in football and boxer players occurred in seven patients (28\%), while road traffic accidents and occupational hazards had been recorded as a cause of auricular hematoma as well (Table 2).

There were two modalities of compression used against the hematoma, the conventional one, here we used the crepe bandage (group A) and the new use of X-ray films (Group B). The complications happened in both groups shown in table 3 , the recurrence happened in one third of the patients in group A, while the recurrence of auricular hematoma not happened in Group B of the patients. Infection occurred in two patients of group A and not in group B, and only one patient

\begin{tabular}{|c|c|c|}
\hline Age (years) & Male & Female \\
\hline $12-20$ & 2 & - \\
\hline $21-30$ & 7 & 2 \\
\hline $31-40$ & 6 & 1 \\
\hline $41-50$ & 4 & 1 \\
\hline $51-60$ & 2 & - \\
\hline Total & 21 & 4 \\
\hline
\end{tabular}

Table 1: Age and sex distribution.

\begin{tabular}{|c|c|c|}
\hline The cause of auricular hematoma & Number & Percentage \\
\hline Personal insult & 10 & 40 \\
\hline Sport injury & 7 & 28 \\
\hline Road traffic accidents & 5 & 20 \\
\hline Occupational hazards & 3 & 12 \\
\hline Total & 25 & 100 \\
\hline \multicolumn{2}{|c|}{ Table 2: The Causes of auricular hematoma. } \\
\end{tabular}

\begin{tabular}{|c|c|c|}
\hline Complications & Number of patients & Percentage \\
\hline Group A (pressure bandage ) & 15 & 60 \\
$-\quad$ - Infection. & 2 & 8 \\
$-\quad$ - Recurrence. & 5 & 20 \\
$-\quad$ - Deformity & 1 & 4 \\
\hline Group B (pressure by X-ray films) & 10 & 40 \\
$-\quad$ - Infection. & 0 & 0 \\
$-\quad$ - Recurrence. & 0 & 0 \\
$-\quad$ - Deformity & 0 & 0 \\
\hline Total & 25 & 100 \\
\hline
\end{tabular}

Table 3: The rate of complications among the different groups ( $a$ and $b$ ) of patients underwent different compression techniques.

developed cauliflower deformity after months in group A as shown in table 3 .

\section{Discussion}

The auricular hematoma is one of the otological emergencies that occurs secondary to trauma; it is represented as one of otologist problems. The mean age of incidence around thirty years and $84 \%$ of the patients were male; these probably represent the age and sex of activity in our society. Regarding the cause of auricular hematoma in this article, $40 \%$ belong to personal insult which was common in our social behavior and ethics. Early interventions in form of simple incision and drainage are mandatory or else growth of ectopic fibroneocartilage derived from the damaged perichondrium will happened [13]. Different modalities of treatment are encountered to relieve hematoma but no clear consensus exists on the best way to do so in order to give best results in concept of cosmoses [6]. Auricular hematoma requires adequate drainage and tight pressure applied to the site for several days [14]. Traditional way of treatment based on incision and drainage or aspiration, and compression dressing technique (conservative techniques) which could be inadequate in the setting of recurrent hematoma [15], so that auricular hematoma is a dilemma usually complicated by recurrence because of failure to apply adequate pressure over the auricle following drainage. Recurrence of the hematoma, however, frequently occurs by use of simple incision or aspiration and a pressure dressing technique [16]. The conservative techniques for the treatment of auricular hematomas are not successful and associated with high rate of recurrence and deformity [17], which was happened in our study when we used it in group A of the patients, here, and the conventional compression by bandage, resulted in one third of the patients developed recurrence. We describe a simple method of splinting the pinna using X-ray films which overcomes this problem. For my knowledge X-ray splint was not used before, it was easy in use and fashioning, convenient, cost effective, no recorded infection or recurrence and it overcame the anoint of the bandaging of the head which produced headache due to pressure upon the head. The most important advantages of the technique were that the obliteration of the subperichondrial space is stable due to fixed pressure, the cosmetic results are good, and the complication rate was low or even not recorded. The reason why compression by X-ray films showed good results over the pressure bandage was that the pressure applied over the subperichondrial space was greater, uniform and more stable. There were different techniques used to carry the same idea of obliteration of subperichondrial space. After incision and evacuation of the fluid, tie-over sutures over wet sponges achieve efficient obliteration of the subperichondrial space [17], through and through sutures, to keep compression in place. Leonard buttons are also effective alternative compressive devices; they are simple to use and easily available [18]. A simple method of treatment with the use of transfixed tie-through compression mattress sutures, incorporating bolster dressings on both 
surfaces of the ear, following drainage of the hematoma via a small skin incision, is presented. This allows an optimal immobilization of the skin over underlying cartilage for 7-10 days, preventing the re-accumulation of fluid with subsequent thickening and fibrosis, frequent complications of the other current methods of treatment [19]. Non-surgical procedures including OK-432 intralesional injection therapy could be used as a substitute for surgical treatment of auricular hematoma, it was simple, safe, easy and effective [20,21]. As a matter of comparison with compression using X-ray films, OK-432 therapy was easier, less invasive but on the other hand it is inconvenient and may be cost ineffective as compared to X-ray compression but the outcome may be the same.

\section{Conclusion}

From this article we concluded that compression of auricular hematoma by X-ray films was easy in use and fashioning, convenient, cost effective and there were no recorded complications.

\section{Acknowledgement}

I would like to express my thanks to all medical and paramedical staff in AlRamadi and Al-Fallujah General Hospitals.

\section{References}

1. Loock JW (2008) Haematoma auris. In: Gleeson M, Browning GG, Burton MJ, Clarke R, Hibbert J, et al. (eds.). Scott-Brown's Otorhinolaryngology, head and Neck Surgery (7thedn) New York, Hodder Arnold 3: 3373-3374.

2. Mudry A, Pirsig W (2009) Auricular hematoma and cauliflower deformation of the ear: from art to medicine. Otol Neurotol 30: 116-120.

3. Greywoode JD, Pribitkin EA, Krein H (2010) Management of auricular hematoma and the cauliflower ear. Facial Plast Surg 26: 451-455.

4. Pandya NJ (1973) Experimental production of "cauliflower ear" in rabbits. Plast Reconstr Surg 52: 534-537.

5. Lane SE, Rhame GL, Wroble RL (1998) A silicone splint for auricular hematoma. Phys Sportsmed 26: 77-78.

6. Jones SE, Mahendran S (2004) Interventions for acute auricular haematoma. Cochrane Database Syst Rev: CD004166.
7. Bingham BJ, Chevretton EB (1987) Silicone ear splints in the management of acute haematoma auris. J Laryngol Otol 101: 889-891.

8. Koopmann CF Jr, Coulthard SW (1979) "How I do it"--otology and neurology: a specific issue and its solution. Management of hematomas of the auricle. Laryngoscope 89: 1172-1174.

9. Eliachar I, Golz A, Joachims HZ, Goldsher M (1983) Continuous portable vacuum drainage of auricular hematomas. Am J Otolaryngol 4: 141-143.

10. Davis PK (1971) An operation for haematoma auris. Br J Plast Surg 24: $277-$ 279.

11. Bull PD, Lancer JM (1984) Surgeon's workshop. Treatment of auricular haematoma by suction drainage. Clin Otolaryngol Allied Sci 9: 355-360.

12. Vuyk HD, Bakkers EJ (1991) Absorbable mattress sutures in the management of auricular hematoma. Laryngoscope 101: 1124-1126.

13. O'Donnell BP, Eliezri YD (1999) The surgical treatment of traumatic hematoma of the auricle. Dermatol Surg 25: 803-805.

14. Lee D, Sperling N (1996) Initial management of auricular trauma. Am Fam Physician 53: 2339-2344.

15. Lee EC, Soliman AM, Kim J (1997) Traumatic auricular hematoma: a case report. J Craniomaxillofac Trauma 3: 32-35.

16. Yamasoba T, Tayama N, Kitamura K (1990) Auricular hematoma--case report of ruptured othematoma and bibliographic review. Nihon Jibiinkoka Gakkai Kaiho 93: 2028-2037.

17. Maurer J, Mann W, Welkoborsky HJ (1990) Therapy of ear hematoma and ear seroma. HNO 38: 214-216.

18. Ho EC, Jajeh S, Molony N (2007) Treatment of pinna haematoma with compression using Leonard buttons. J Laryngol Otol 121: 595-596.

19. Robotti E, Verna G (1990) Treatment of traumatic oto-hematoma with transfixed compression sutures. Minerva Chir 45: 285-288.

20. Kubota T, Ohta N, Fukase S, Kon Y, Aoyagi M (2010) Treatment of auricular hematoma by OK-432. Otolaryngol Head Neck Surg 142: 863-866.

21. Ohta N, Fukase S, Suzuki Y, Ishida A, Aoyagi M (2010) Treatments of various otolaryngological cystic diseases by OK-4321: its indications and limitations. Laryngoscope 120: 2193-2196. 